\title{
An updated overview of clinical guidelines for the management of non-specific low back pain in primary care
}

\author{
Bart W. Koes $\cdot$ Maurits van Tulder • \\ Chung-Wei Christine Lin • Luciana G. Macedo • \\ James McAuley $\cdot$ Chris Maher
}

Received: 30 October 2009/Revised: 15 June 2010/Accepted: 16 June 2010/Published online: 3 July 2010

(C) The Author(s) 2010. This article is published with open access at Springerlink.com

\begin{abstract}
The aim of this study was to present and compare the content of (inter)national clinical guidelines for the management of low back pain. To rationalise the management of low back pain, evidence-based clinical guidelines have been issued in many countries. Given that the available scientific evidence is the same, irrespective of the country, one would expect these guidelines to include more or less similar recommendations regarding diagnosis and treatment. We updated a previous review that included clinical guidelines published up to and including the year 2000 . Guidelines were included that met the following criteria: the target group consisted mainly of primary health care professionals, and the guideline was published in English, German, Finnish, Spanish, Norwegian, or Dutch. Only one guideline per country was included: the one most recently published. This updated review includes national clinical guidelines from 13 countries and 2 international clinical guidelines from Europe published from 2000 until 2008. The content of the guidelines appeared to be quite similar regarding the diagnostic classification (diagnostic triage) and the use of diagnostic and therapeutic interventions.
\end{abstract}

B. W. Koes $(\square)$

Department of General Practice, Erasmus MC, P.O. Box 2040, 3000 CA Rotterdam, The Netherlands e-mail: b.koes@erasmusmc.nl

M. van Tulder

Department of Health Sciences and the EMGO Institute for Health and Care Research, VU University Amsterdam, Amsterdam, The Netherlands

C.-W. C. Lin · L. G. Macedo - J. McAuley · C. Maher

George Institute, Sydney, Australia
Consistent features for acute low back pain were the early and gradual activation of patients, the discouragement of prescribed bed rest and the recognition of psychosocial factors as risk factors for chronicity. For chronic low back pain, consistent features included supervised exercises, cognitive behavioural therapy and multidisciplinary treatment. However, there are some discrepancies for recommendations regarding spinal manipulation and drug treatment for acute and chronic low back pain. The comparison of international clinical guidelines for the management of low back pain showed that diagnostic and therapeutic recommendations are generally similar. There are also some differences which may be due to a lack of strong evidence regarding these topics or due to differences in local health care systems. The implementation of these clinical guidelines remains a challenge for clinical practice and research.

Keywords Low back pain - Clinical guidelines · Review · Diagnosis · Treatment

\section{Introduction}

Low back pain remains a condition with a relatively high incidence and prevalence. Following a new episode, the pain typically improves substantially but does not resolve completely during the first 4-6 weeks. In most people the pain and associated disability persist for months; however, only a small proportion remains severely disabled [1]. For those whose pain does resolve completely, recurrence during the next 12 months is not uncommon [2, 3].

There is a wide acceptance that the management of low back pain should begin in primary care. The challenge for primary care clinicians is that back pain is but one of many 
conditions that they manage. For example while back pain, in absolute numbers, is the eighth most common condition managed by Australian GPs, it only accounts for $1.8 \%$ of their case load [4]. To assist primary care practitioners to provide care that is aligned with the best evidence, clinical practice guidelines have been produced in many countries around the world.

The first low back pain guideline was published in 1987 by the Quebec Task Force with authors pointing to the absence of high-quality evidence to guide decision making [5]. Since that time there has been a strong growth in research addressing diagnosis and prognosis but especially research on therapy. As an example of this growth, at the time of the Spitzer guideline [5] there were only 108 randomised controlled trials evaluating physiotherapy treatments for low back pain but as at April 2009 there were 958. ${ }^{1}$ The Cochrane database (Central) currently lists more than 2500 controlled trials evaluating treatment for back and neck pain. The evidence from these trials for most interventions is summarised in systematic reviews and meta-analysis. The Cochrane Back Review Group, for example, has now published 32 systematic reviews of randomised controlled trials evaluating interventions for low back pain. In the near future, systematic reviews of studies evaluating diagnostic intervention for low back pain will also be included in the Cochrane Library.

This dramatic growth in research would be a comfort to those who were members of the original Quebec Task Force but perhaps a challenge to those who served on committees for later guidelines. With a large and ever increasing research base to inform guidelines two potential problems arise. The first and most obvious is that the recommendations in the guidelines may become out of date. The second is that with a wealth of information to consider, the various committees producing guidelines may produce quite different treatment recommendations. At the same time one can argue that if more precise and valid information becomes available recommendations will become more similar. A previous systematic review of clinical practice guidelines was conducted in 2001 [6]. In that review we assessed the available clinical guidelines from 11 countries and concluded that the guidelines provided generally similar recommendations regarding the diagnostic classification (diagnostic triage) and the use of diagnostic and therapeutic interventions. Consistent features were the early and gradual activation of patients, the discouragement of prescribed bed rest, and the recognition of psychosocial factors as risk factors for chronicity. However, there were discrepancies for recommendations

\footnotetext{
$\overline{1}$ Based upon search of PEDro database April 29, 2009.
}

regarding exercise therapy, spinal manipulation, muscle relaxants, and patient information.

Bouwmeester et al. [7] concluded recently that the quality of mono- and multidisciplinary clinical guidelines for the management of low back pain, as measured with the AGREE instrument has improved over time. The present article focuses on the actual content of national clinical guidelines on low back pain which have been issued since 2001. These guidelines are compared regarding the content of their recommendations, the target group, the guideline committee and its procedures, and the extent to which the recommendations were based on the available literature (the scientific evidence). We also highlight any changes in recommendations that have occurred over time in comparison with our previous review [6].

\section{Methods}

Clinical guidelines were searched using electronic databases covering the period 2000-2008: Medline (key words: low back pain, clinical guidelines), PEDro (key words: low back pain, practice guidelines, combined with AND), National Guideline Clearinghouse (www.guideline.gov; key word: low back pain), and National Institute for Health and Clinical Excellence (NICE) (www.nice.org.uk; key word: low back pain). Guidelines used in the previous review were checked for updates. We also checked the content and reference list of relevant reviews on guidelines, included a search on the Web of Science citation index for articles citing the previous review and asked experts in the field. To be included in this review, the guidelines had to meet the following criteria: (1) the guideline concerned the diagnosis and clinical management of low back pain, (2) the guideline was targeted at a multidisciplinary audience in the primary care setting, and (3) the guideline was available in English, German, Finnish, Spanish, Norwegian or Dutch because documents in these languages could be read by the reviewers. Only one guideline was included per country unless there were separate guidelines for acute and chronic low back pain. Where more than one eligible guideline was available for a country, we included the most recent guideline issued by a national body. Guidelines from the following countries/regions and agencies (year of publication) were included:

Australia, National Health and Medical Research Council (2003) [8];

Austria, Center for Excellence for Orthopaedic Pain Management Speising (2007) [9];

Canada, Clinic on Low back Pain in Interdisciplinary Practice (2007) [10];

Europe, COST B13 Working Group on Guidelines for the Management of Acute Low Back Pain in Primary Care (2004) [11]; 
Europe, COST B13 Working Group on Guidelines for the Management of Chronic Low Back Pain in Primary Care (2004) [12];

Finland, Working group by the Finnish Medical Society Duodecim and the Societas Medicinae Physicalis et Rehabilitationis Fenniae. Duodecim (2008) [13];

France, Agence Nationale d'Accreditation et d'Evaluation en Sante (2000) [14];

Germany, Drug Committee of the German Medical Society (2007) [15];

Italy, Italian Scientific Spine Institute (2006) [16];

New Zealand, New Zealand Guidelines Group (2004) [17];

Norway, Formi \& Sosial- og helsedirectorated (2007) [18];

Spain, the Spanish Back Pain Research Network (2005) [19];

The Netherlands, The Dutch Institute for Healthcare Improvement (CBO) (2003) [20];

United Kingdom, National Health Service (2008) [21]; and

United States, American College of Physicians and the American Pain Society (2007) [22].

Data regarding the diagnostic and therapeutic recommendations as well as background information of the guideline process were extracted from the guidelines by four of the authors, each assessing 3-4 guidelines. The Finnish and Norwegian guidelines were assessed by colleagues with relevant language skills from The Netherlands and Finland. The focus was on the process of guideline development and the recommendations for diagnosis and treatment. We used the same data categories as in the previous review to facilitate comparisons (see Tables 1, 2, 3).

\section{Results}

Patient population

Each of the guidelines considered the duration of symptoms but they vary in their scope and definitions. For example, the guidelines from Australia and New Zealand focus on acute low back pain whereas the guidelines from Austria and Germany consider acute, subacute, chronic and recurrent low back pain. The cut-off for chronic is not always specified but when it was, 12 weeks was used. Sometimes the word persistent rather than chronic was used. Two guidelines (Austrian and German) provide recommendations for recurrent low back pain but do not explicitly define 'recurrent'.
Diagnostic recommendations

Table 1 compares the diagnostic classification and the recommendations on diagnostic procedures in the various guidelines. All guidelines recommend a diagnostic triage where patients are classified as having (2) non-specific low back pain, (2) suspected or confirmed serious pathology ('red flag' conditions such as tumour, infection or fracture) and (3) radicular syndrome. Some guidelines, e.g. the Australian and New Zealand guidelines, do not distinguish between non-specific low back pain and radicular syndrome. The German guideline also classifies a group of patients who are at risk for chronicity, based on 'yellow flags'.

All guidelines are consistent in their recommendations that diagnostic procedures should focus on the identification of red flags and the exclusion of specific diseases (sometimes including radicular syndrome). Red flags include, for example, age at onset $(<20$ or $>55$ years), significant trauma, unexplained weight loss and widespread neurologic changes. The types of physical examination and physical tests that are recommended show some variation. Some, such as the European guideline, limit the examination to a neurological screen whereas others advocate a more comprehensive musculoskeletal (including inspection, range of motion/spinal mobility, palpation, and functional limitation) and neurological examination. The components of the neurologic screening are not always explicit but where they are, comprise testing of strength, reflexes, sensation and straight leg raising.

None of the guidelines recommend routine use of imaging, with imaging recommended at the initial visit only for cases of suspected serious pathology (e.g. Australian, European) or where the proposed treatment (e.g. manipulation) requires the exclusion of a specific cause of low back pain (French). Imaging is sometimes recommended where sufficient progress is not being made but the time cut-off varies from 4 to 7 weeks. Guidelines often recommend MRI in cases with red flags (e.g. European, Finland, Germany).

All guidelines mention psychosocial factors associated with poor prognosis with some describing them as 'yellow flags'. There is, however, considerable variation in the amount of details given about how to assess 'yellow flags' or the optimal timing of the assessment. The Canadian and the New Zealand guidelines provide specific tools for identifying yellow flags and clear guidelines for what should be done once yellow flags are identified. 


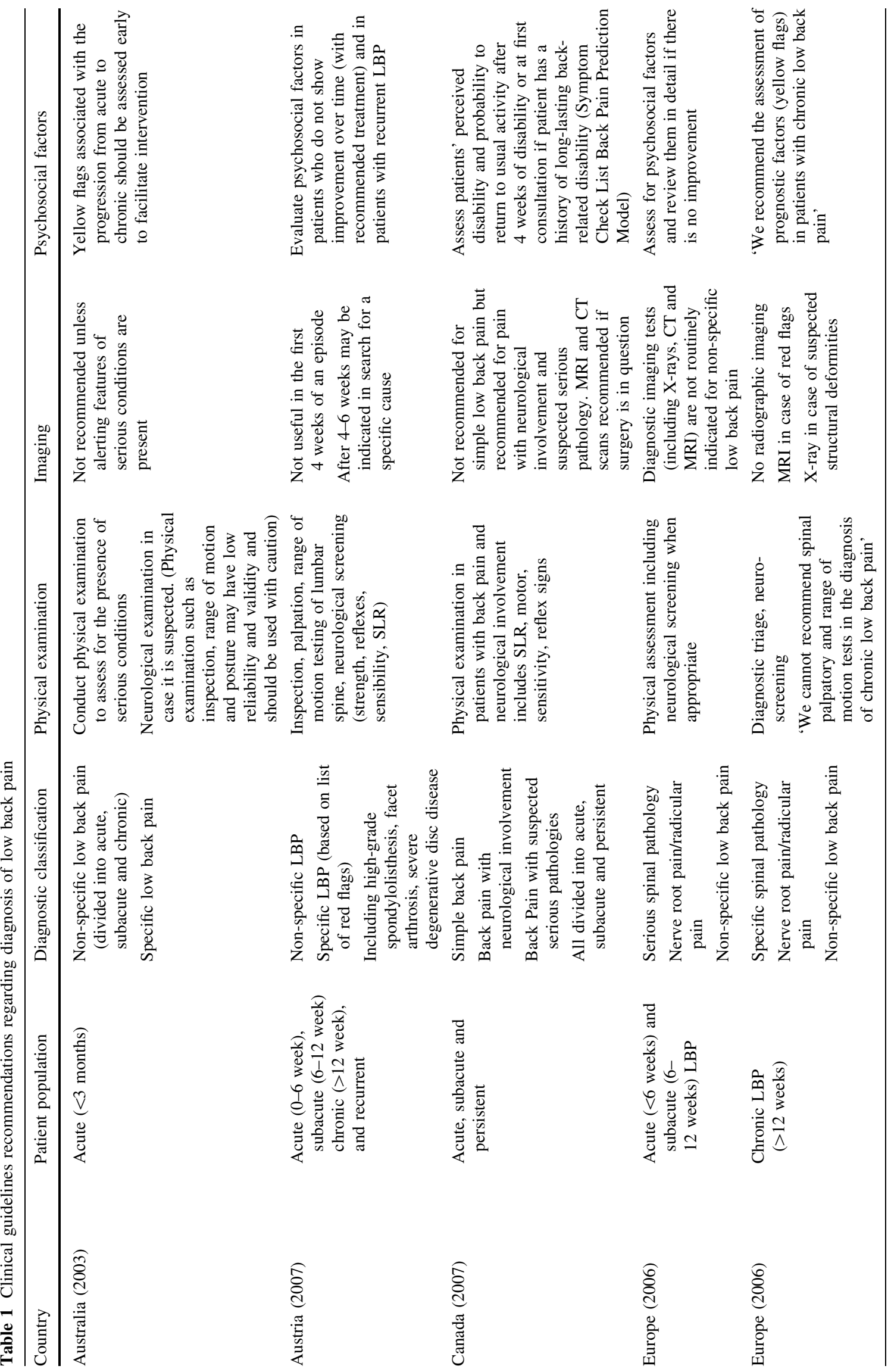




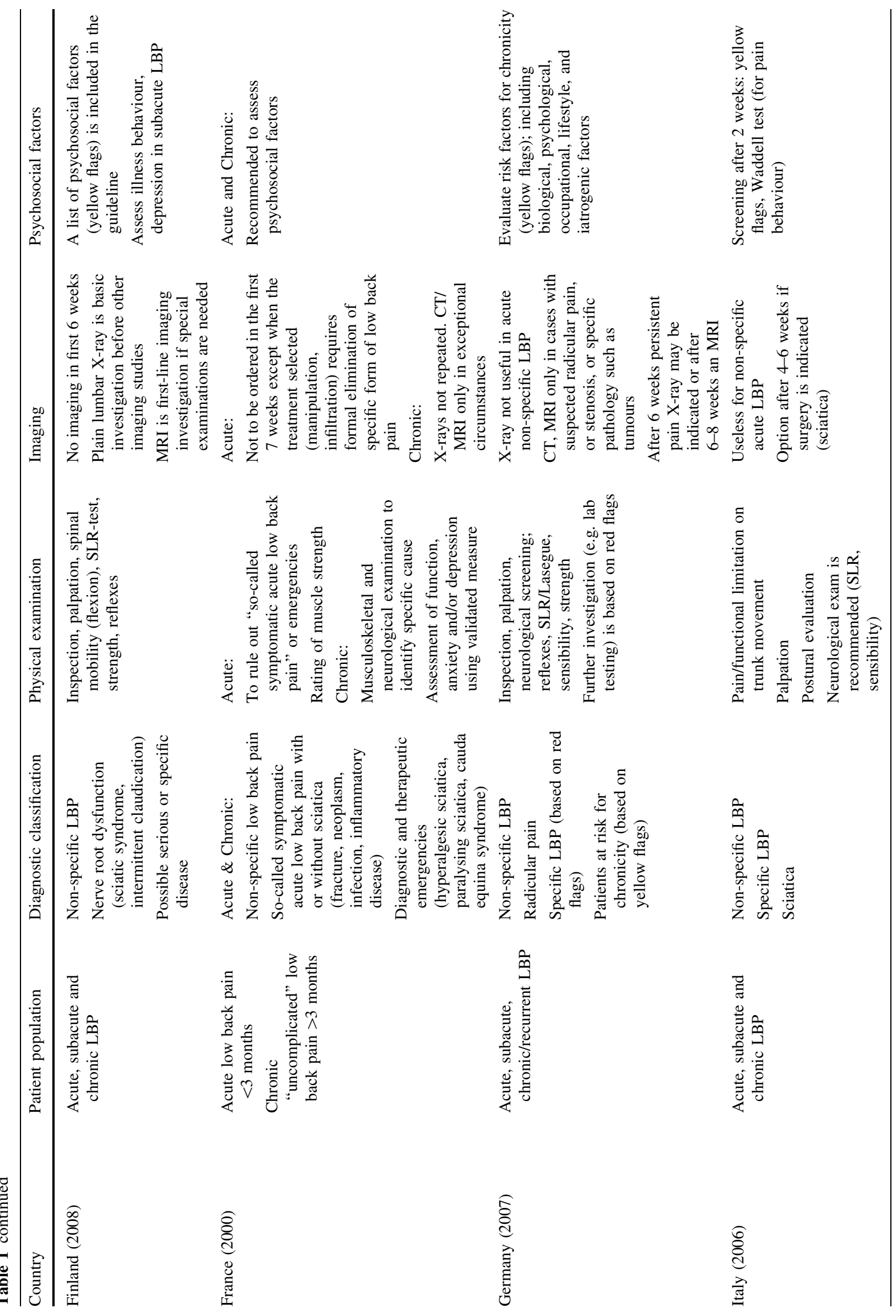




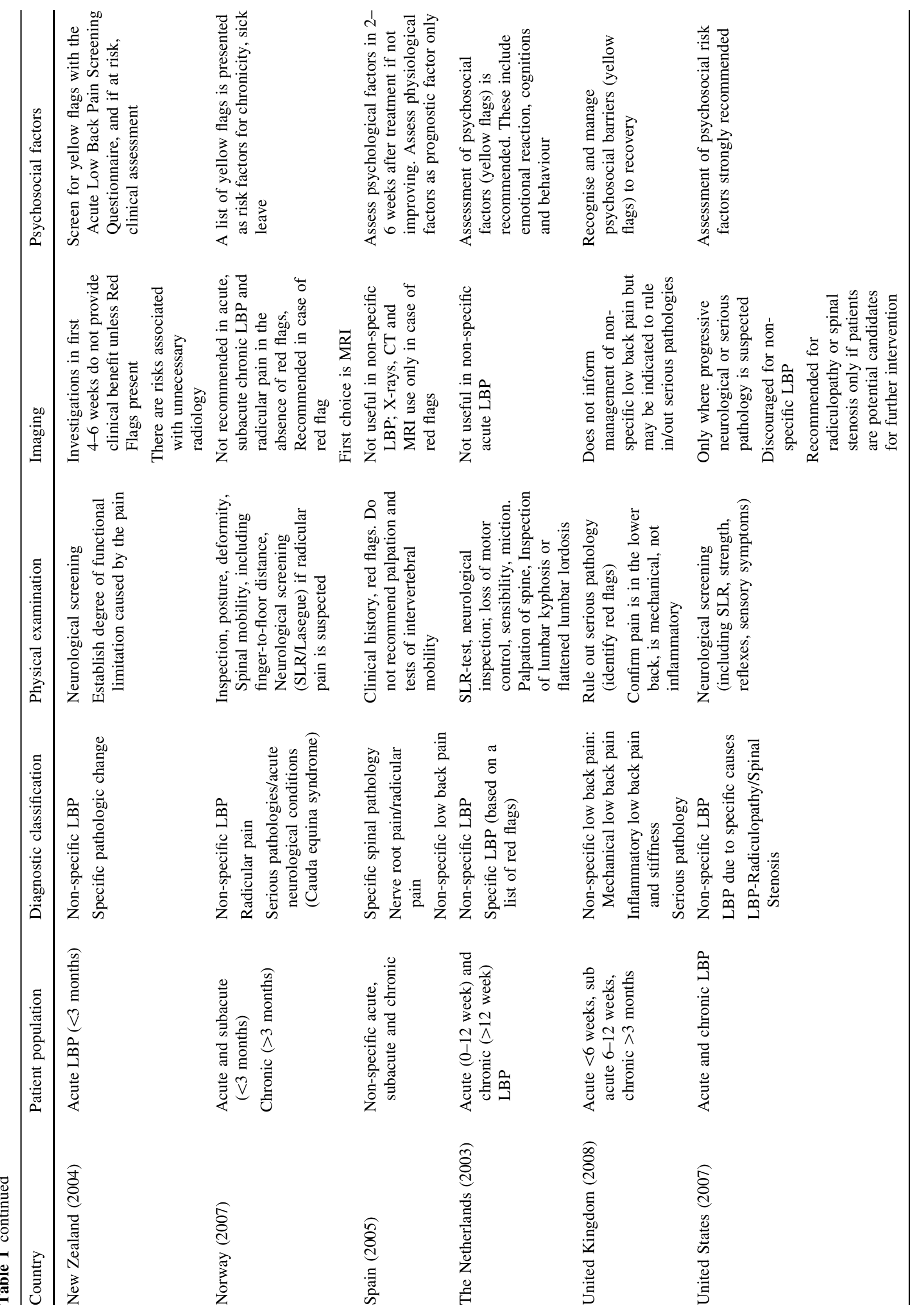




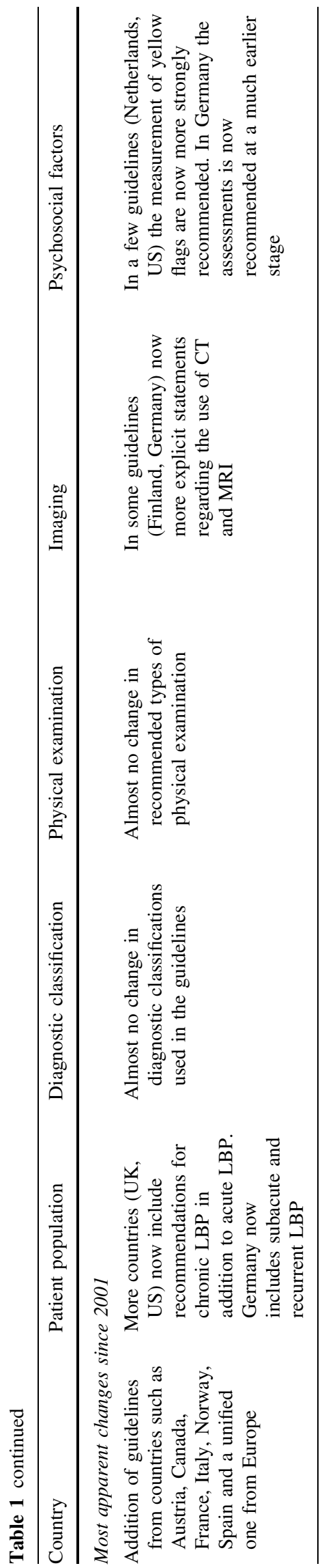

Summary of Common Recommendations for Diagnosis of Low back pain

* Diagnostic triage (non-specific low back pain, radicular syndrome, serious pathology).

* Screen for serious pathology using red flags.

* Physical examination for neurologic screening (including straight leg raising test).

* Consider psychosocial factors (yellow flags) if there is no improvement.

* Routine imaging not indicated for non-specific low back pain.

Therapeutic recommendations

Table 2 compares therapeutic recommendations given in the various guidelines. Patient advice and information is recommended in all guidelines. The common message is that patients should be reassured that they do not have a serious disease, that they should stay as active as possible and progressively increase their activity levels. Compared with the previous review, the current guidelines increasingly mention early return to work (despite having low back pain) in their list of recommendations.

Recommendations for the prescription of medication are generally consistent. Paracetamol/acetaminophen is usually recommended as a first choice because of the lower incidence of gastrointestinal side effects. Nonsteroidal anti-inflammatory drugs are the second choice in cases where paracetamol is not sufficient. There is some variation between guidelines with regard to recommendations for opioids, muscle relaxants, steroids, antidepressant and anticonvulsive medication as co-medication for pain relief. Where the mode of consumption of analgesics is described, time-contingent rather than paincontingent use, is advocated.

There is now broad consensus that bed rest should be discouraged as a treatment for low back pain. Some guidelines state that if bed rest is indicated because of severity of pain, then it should not be advised for more than 2 days (e.g., Germany, New Zealand, Spain, Norway). The Italian guideline advises 2-4 days of bed rest for major sciatica but does clearly describe how major sciatica differs from sciatica where bed rest is contraindicated.

There is also consensus that a supervised exercise programme (as distinct from encouraging resumption of normal activity) is not indicated for acute low back pain. Those guidelines that consider subacute and chronic low back pain recommend exercise but note that there is no evidence that one form of exercise is superior to another. The European guideline advises against exercise that requires expensive training and machines. The one area of 


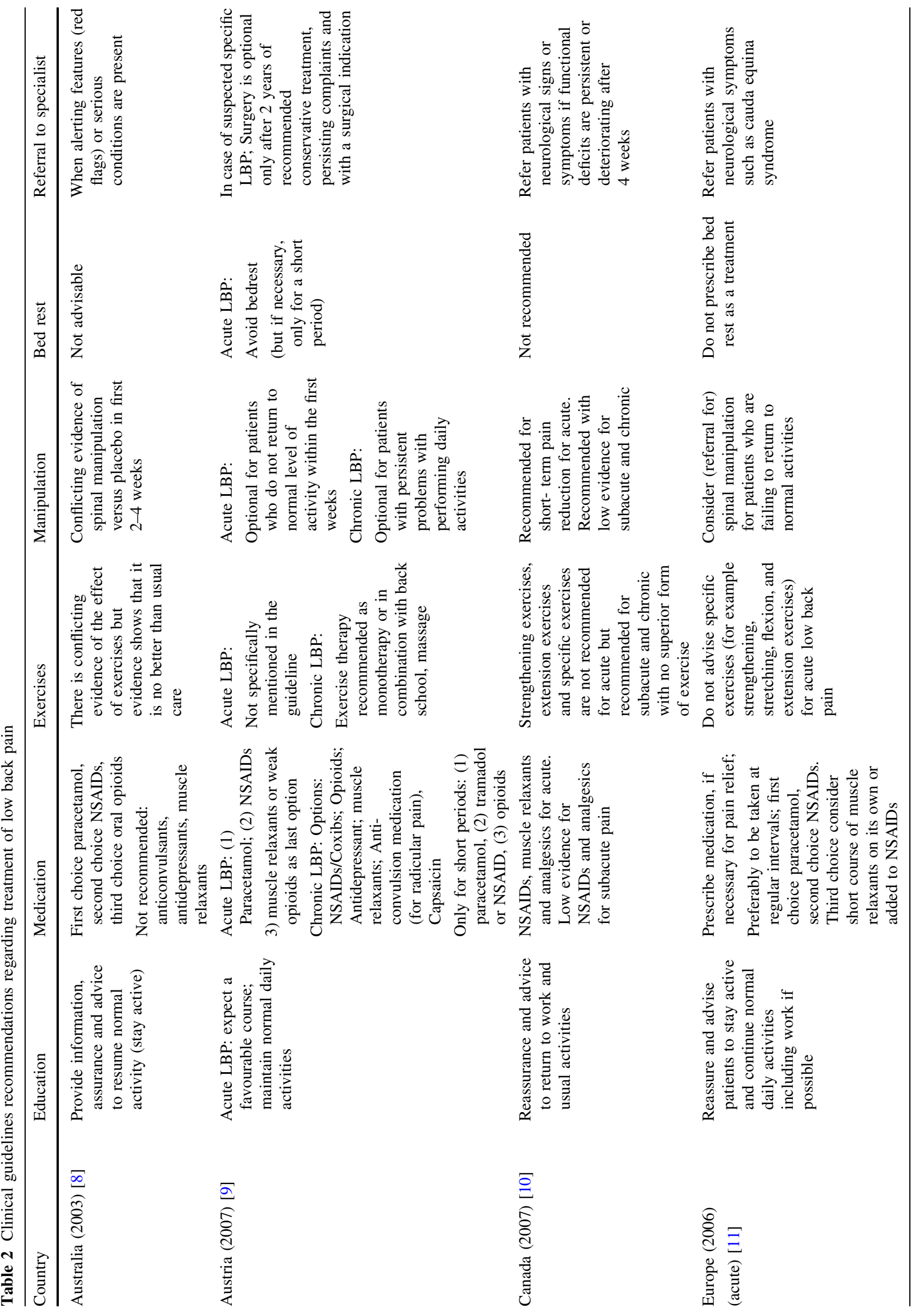




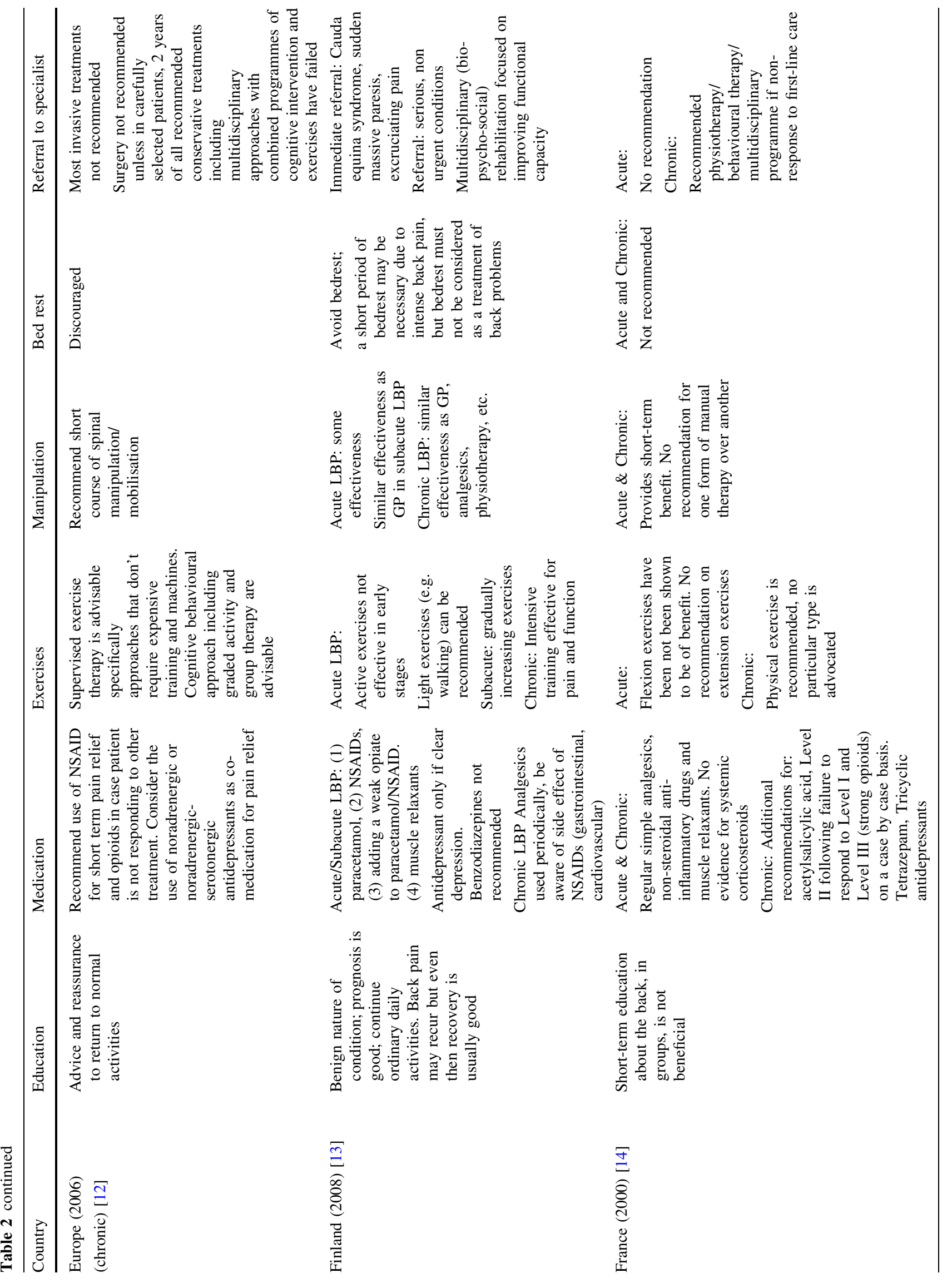




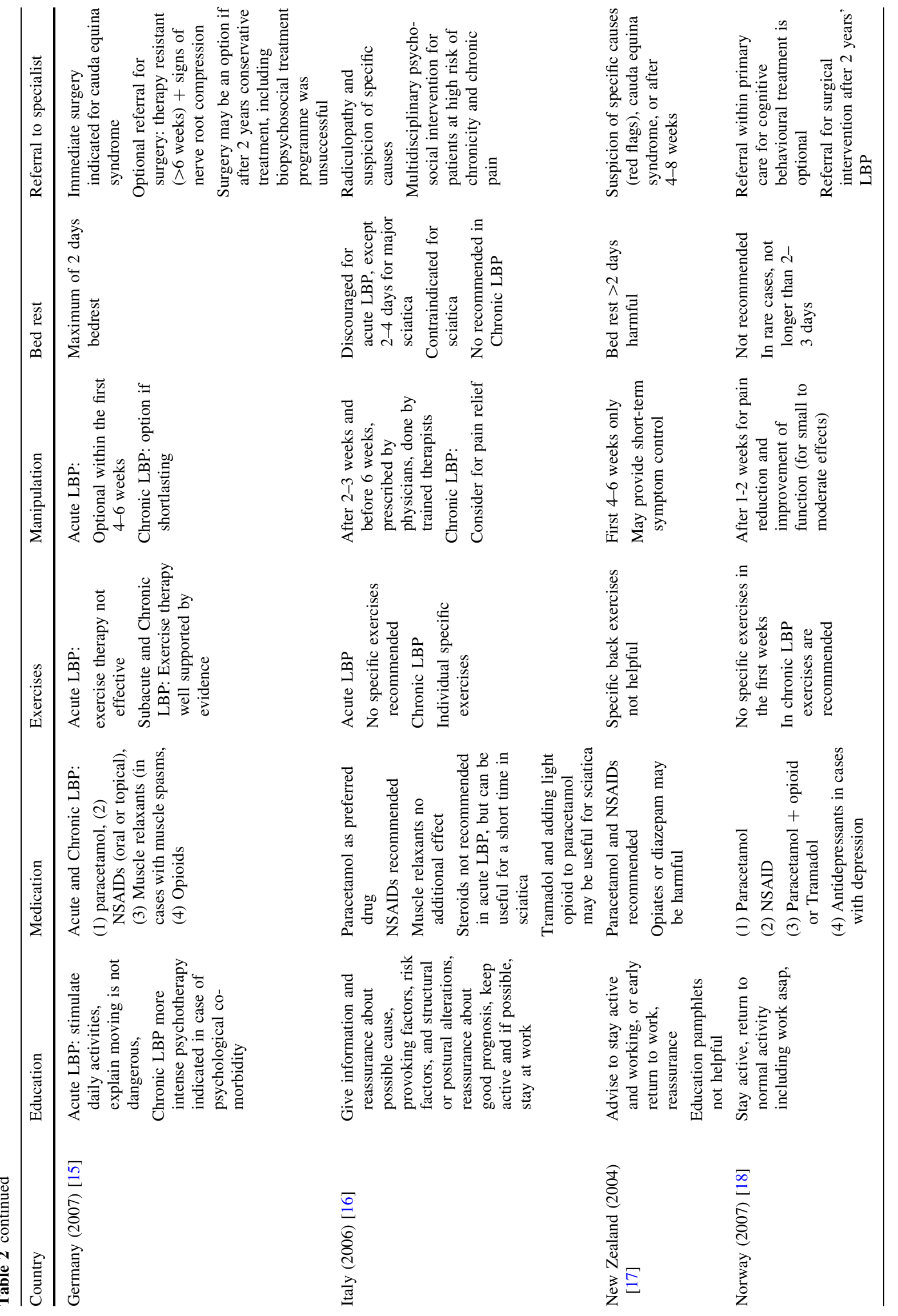




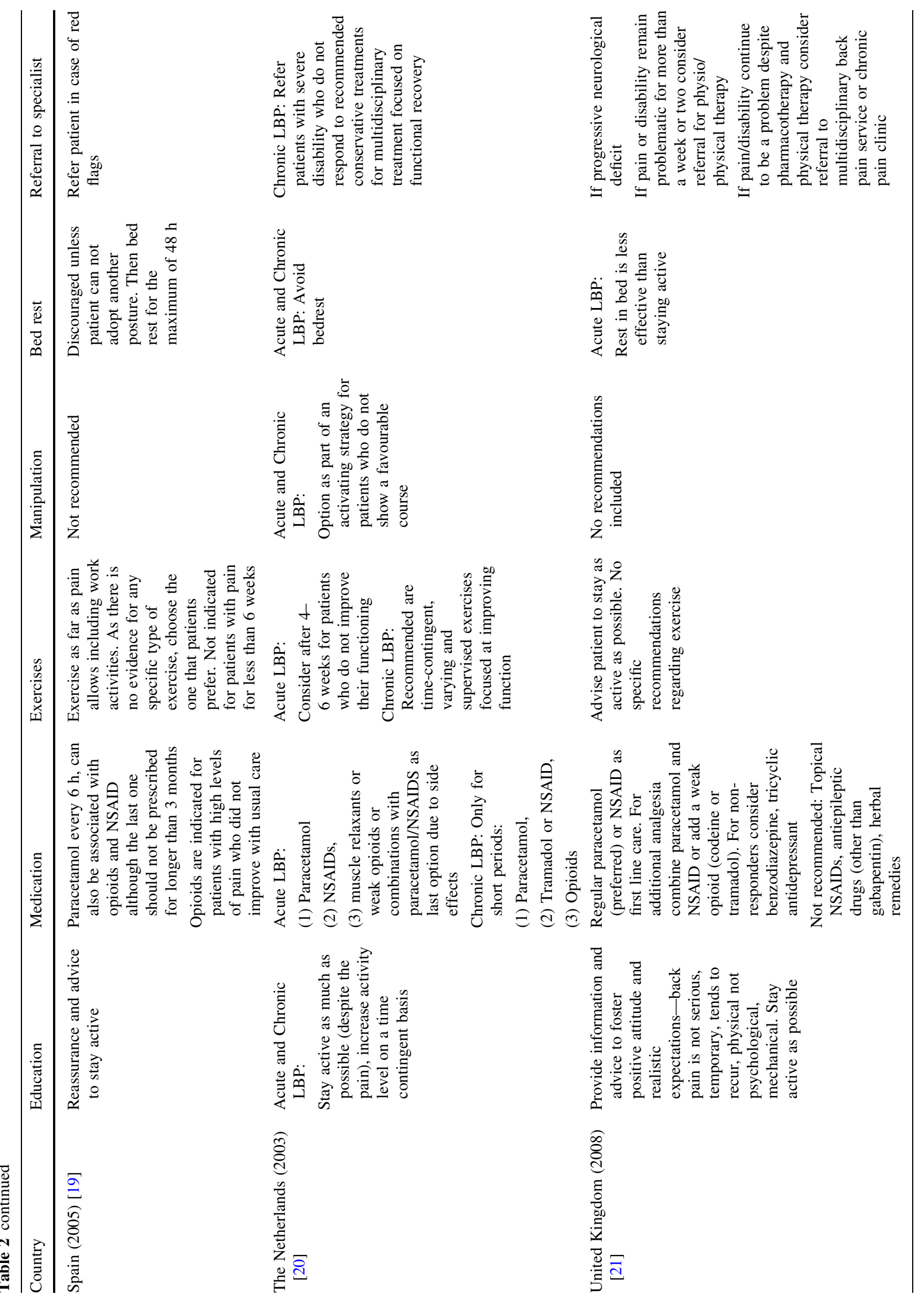




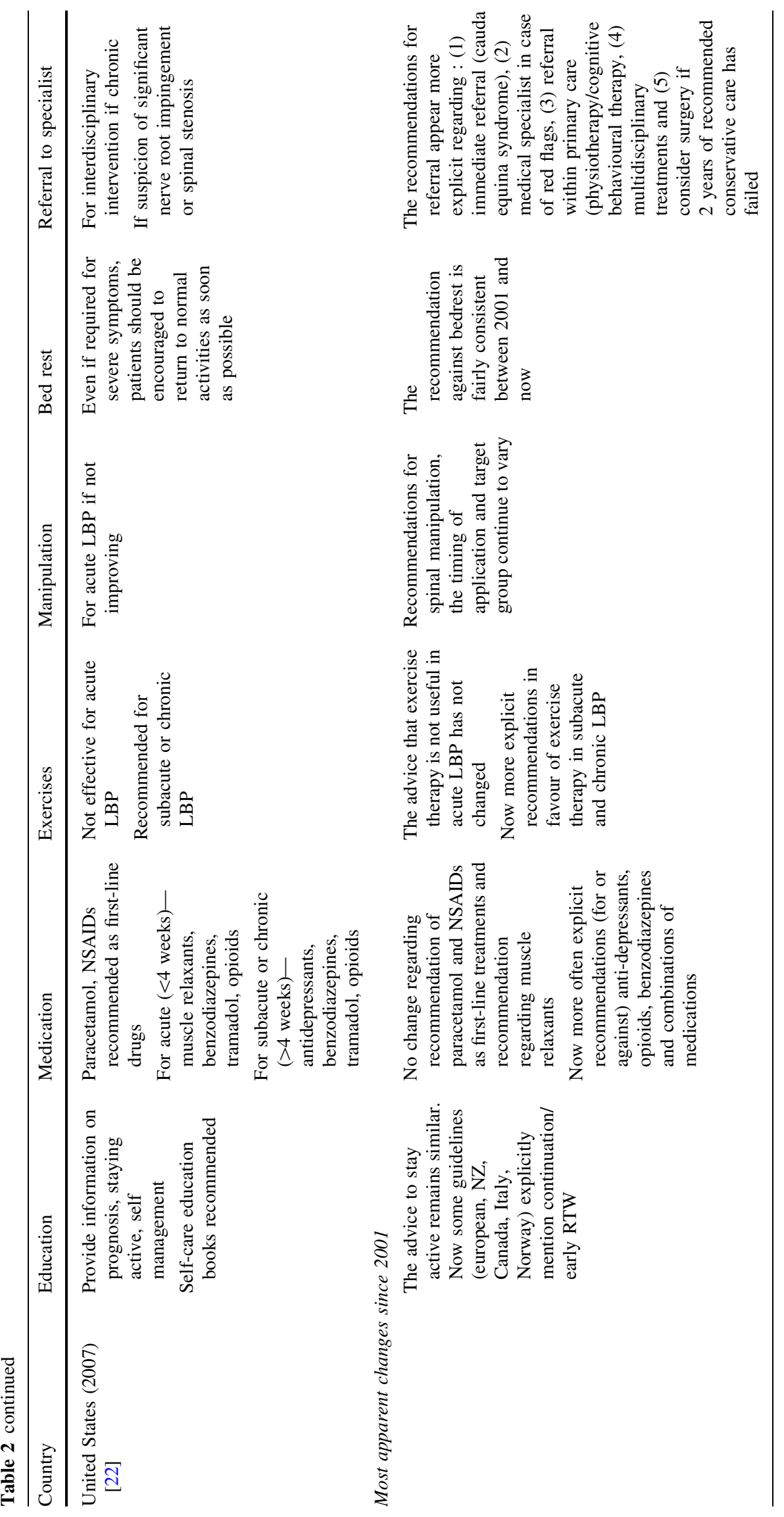


therapy that is contentious is the use of spinal manipulation. Some guidelines do not recommend the treatment (e.g. Spanish, Australian), some advise that it is optional (e.g. Austrian, Italian) and some suggest a short course for those who do not respond to the first line of treatment (e.g. US, the Netherlands). For some it is optional only in the first weeks of an episode in acute low back pain (e.g. Canada, Finland, Norway, Germany, New Zealand). The French guideline advises that there is no evidence to recommend one form of manual therapy over another.

\footnotetext{
Summary of Common Recommendations for Treatment of Low back pain

Acute or Subacute Pain

* Reassure patients (favourable prognosis).

* Advise to stay active.

* Prescribe medication if necessary (preferably time-contingent): first line is paracetamol; second line is nonsteroidal antiinflammatory drugs, consider muscle relaxants, opioids or antidepressant and anticonvulsive medication (as co-medication for pain relief).

* Discourage bed rest.

* Do not advise a supervised exercise programme.

Chronic Pain

* Discourage use of modalities (such as ultrasound, electrotherapy)

* Short-term use of medication/manipulation

* Supervised exercise therapy

* Cognitive behavioural therapy

* Multidisciplinary treatment
}

\section{Evidence-based review}

All guidelines are more or less based on a comprehensive literature search, including Cochrane Library, Medline, Embase. Some committees (Austria, Germany, Spain) based their recommendations, entirely or in part, on the European guidelines. Most guidelines use an explicit weighting of the strength of the evidence.

The Dutch, UK, European, Finnish, German, Norwegian and Australian guidelines give direct links between the actual recommendations and the evidence (via specific references) on which the recommendations are based. Other guidelines do not present a direct link but state that for recommendation there is at least moderate or fair evidence (New Zealand, US). Most committees use consensus methods, mostly by group discussions when the evidence was not convincing or not available.

\section{Presentation and implementation}

The activities related to the publication and dissemination of the various guidelines show some differences and some similarities. In most cases, the guidelines are accompanied by easily accessible summaries for practitioners and booklets for patients. Systematic implementation activities are rare. In most cases, the printed versions of the guidelines are published in national journals and/or disseminated through professional organisations to the target practitioners. Most guidelines are available on the websites of participating organisation. In many countries, regular updates of the guidelines are planned with time horizons of $3-5$ years.

\section{Discussion}

In the past decade many countries have issued (updated) clinical guidelines for the management of low back pain. In general these guidelines provide similar advice on the management of low back pain. Common recommendations are the diagnostic triage of patients with low back pain, restricted use of radiographs, advice on early and progressive activation of patients, and the related discouragement of bed rest. The recognition of psychosocial factors as a risk factor for chronicity is also consistent across all guidelines, though with varying emphasis and detail. There are also differences in the recommendations provided by the guidelines, but these are few and probably less than could expected for different health care systems and cultures. One of the reasons for the similarity of the guidelines might be that guideline committees are usually aware of the content of other guidelines and are motivated to produce similar recommendations that are deemed 


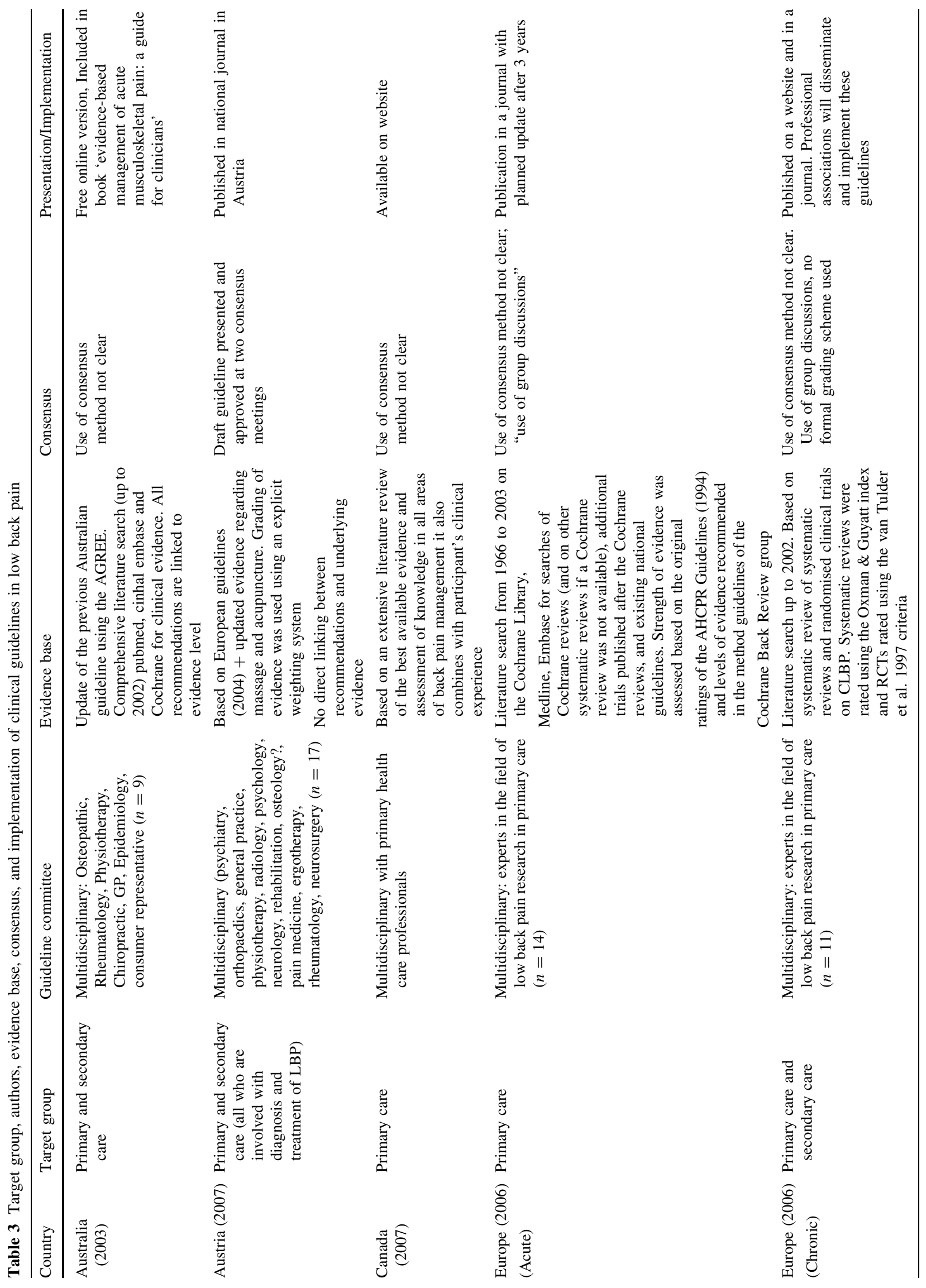




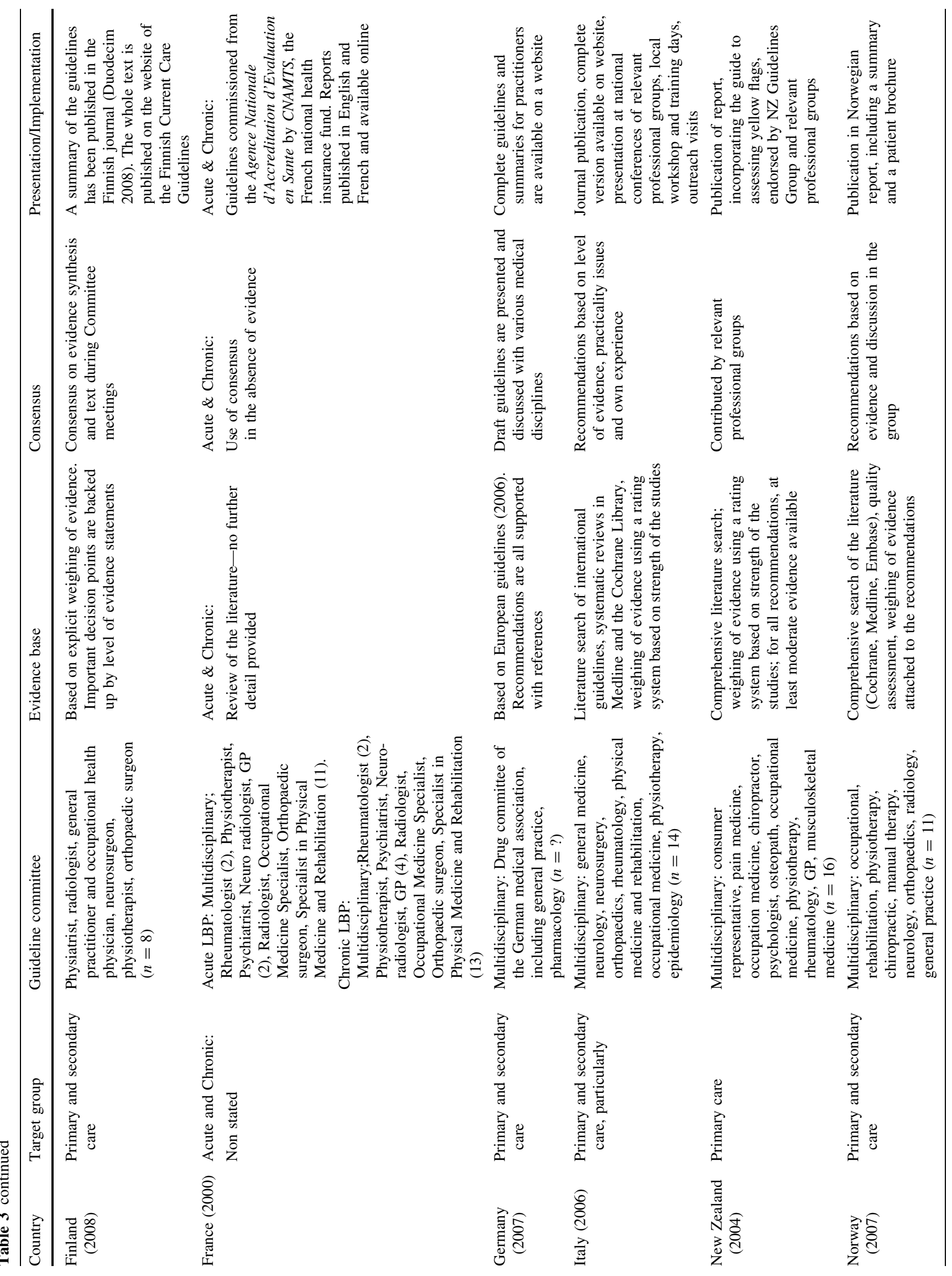




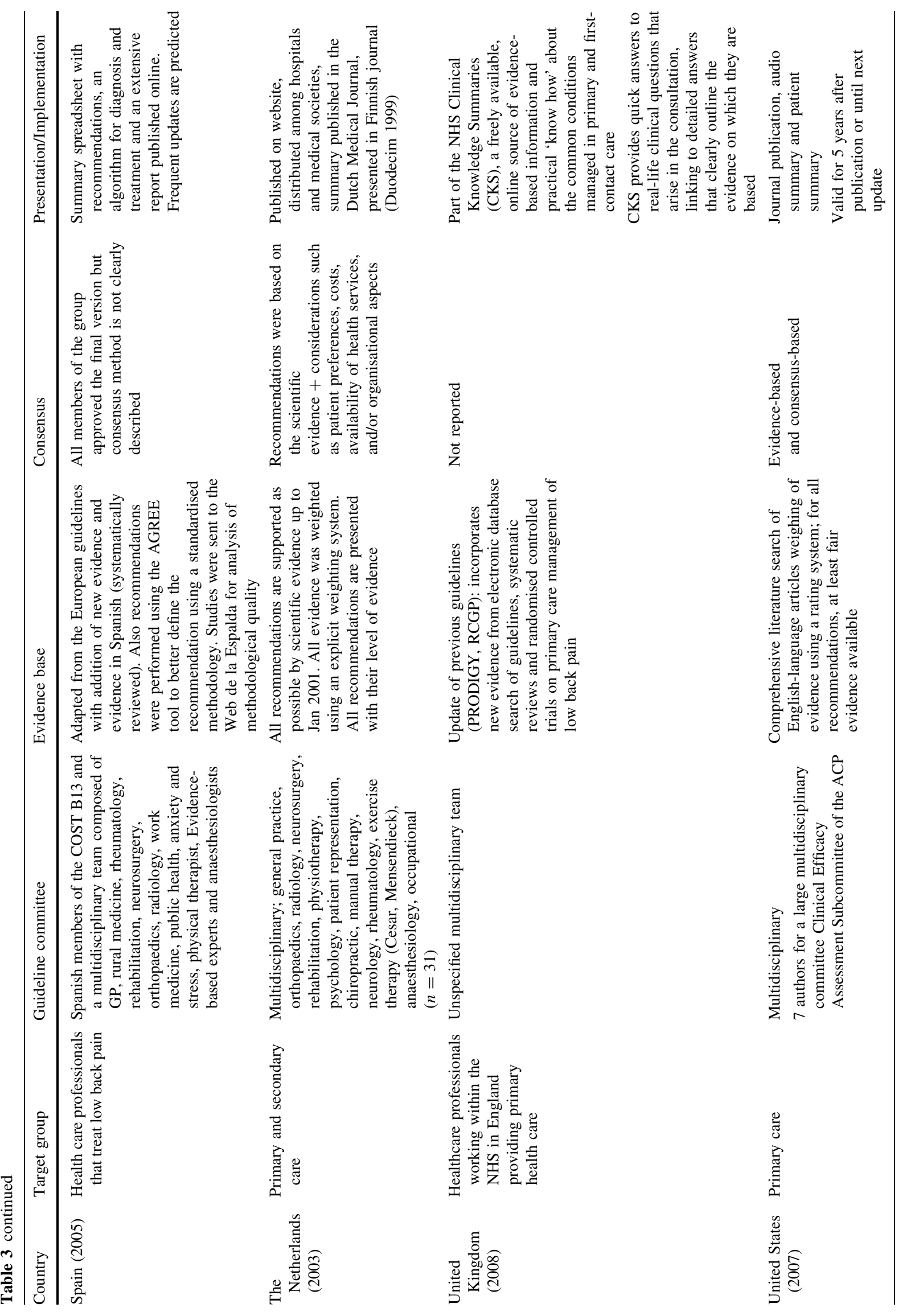




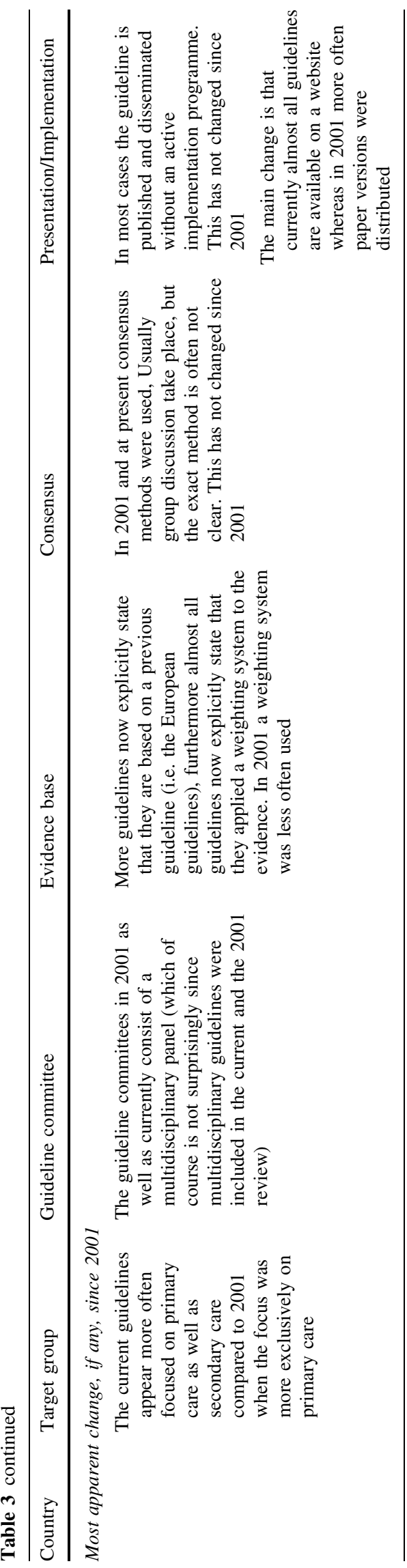

sensible and relevant. In some instances the guidelines are a national adaptation (e.g. in Spain) of the European guidelines.

We do not present an exhaustive overview of all clinical guidelines available, but focused on national multidisciplinary guidelines. This enables a reasonable comparison of recommended approaches across countries. A limitation is thus that not all available guidelines, including monodisciplinary guidelines, are included.

Use of available evidence

Most reviews are based on extensive literature reviews. Cochrane reviews are frequently used, comprehensive searches in databases such as Medline, Embase and PEDro. Increasingly the literature reviews of other and previous guidelines are used as starting point for the (additional) searches. Most committees also use some kind of weighting system and rating of the evidence. There is some variation in the way the recommendations are presented. In some guidelines all the recommendations are directly linked with references to the supporting evidence, and in others a general remark is made that for all recommendations that there is at least moderate evidence available.

\section{Differences in recommendations}

Recommendations about the prescription of analgesic medication remain fairly consistent. Most guidelines recommend paracetamol as the first option and nonsteroidal anti-inflammatory preparations as the second option. Further recommendations about other drugs like opioids, muscle relaxants and benzodiazepines and antidepressants vary quite considerably. Part of these variations might reflect the setting and custom in different countries. Since all the guidelines were issued within a relative short time frame, the availability of underlying evidence did not vary much.

The recommendations regarding spinal manipulation continue to show some variation. In some guidelines manipulation is recommended, or presented as a therapeutic option, usually for short-term benefit, but others do not recommend it. This holds true for acute as well as chronic low back pain. The reasons for these differences remain speculative. Probably the underlying evidence is not strong enough to result in similar recommendations regarding manipulation across all guidelines, leaving the committees some more room for interpretation, but also local or political reasons may be involved.

There is now relatively large consensus across the various guidelines that specific back exercises (as opposed to the advice to stay active, including for example walking, cycling) are not recommended for patients with acute low 
back pain. At the same time back exercises are recommended in chronic low back pain. Most guidelines do not recommend a particular type of exercises for chronic low back pain, but some state that they should be intense.

Recommendations in guidelines are based not only on scientific evidence but also on consensus and discussion in the guideline committees. Usually it is stated that consensus was based on group discussion, but the details of these discussions are seldom reported. It is also generally unclear which recommendations are based mainly on scientific evidence and which are based on (mainly) consensus.

There is little information on whether cost-effectiveness played an important role as a basis for the recommendation in a guideline. Of course, there are not yet many costeffectiveness studies available [23], but it is not fully clear to what extent the published studies were used.

Most guidelines state that the prognosis of an episode of low back pain is good. This holds especially true for patients with acute episodes of low back pain. For patients presenting with a longer duration with low back pain or with recurrent low back pain the prognosis may be less favourable. More individualised and precise estimates of the prognosis of an episode of low back pain may be desirable in the future.

Few changes in management recommendations over time

This update showed that overall the recommendations in the current guidelines regarding diagnosis and treatment of low back pain did not change substantially compared to the guidelines issued about a decade ago. This may well illustrate the lack of new evidence showing better results with new diagnostic and therapeutic approaches and/or new evidence showing the inefficacy of existing interventions. A less nihilistic view could be that already a decade ago the most valid recommendations for the management of low back pain were identified. Some may argue that this is indeed the case, and that much more effort should now be given to implementation of guidelines (see below).

Some recommendations did change over time. We now see diagnostic recommendations appearing concerning the value of MRI and CT scans (i.e. in relation to exclusion and further diagnosis of red flags and serious spinal disorders). However, these recommendations are not yet strong, possibly because there are not many diagnostic studies available evaluating the value of MRI in patients with low back pain. Also, the recommendations regarding the assessment of psychosocial risk factors for chronicity are more firm in the current guidelines than that a decade ago. This reflects the insight of the importance of these risk factors for the development of chronicity and future disability. At the same time we must conclude that we are not yet very successful in effective screening of the patients at risk and subsequent therapeutic management of them [24].

Most apparent changes regarding therapeutic interventions include the advice to continue work (despite having low back pain) and or return to work as soon as possible. There are now more recommendations of second line medications such as antidepressants, opioids, benzodiazepines and compound medications. But these recommendations are not consistent across countries, potentially because of weak underlying evidence. There are now also more firm recommendations in favour of exercise therapy in patients with subacute and chronic low back pain. The latter is partly due to the fact that currently more guidelines include recommendation for the management of chronic low back pain as compared to a decade ago. Finally, the reasons and options for referral within primary care and secondary care are now more explicitly presented. It appears that the global approach regarding the management of low back pain remained largely unchanged in the past decade, although some refinements have been suggested.

\section{Implementation}

The extent to which currently available guidelines are used and followed in the various countries remains largely unknown. A few studies evaluating various implementation strategies for low back pain guidelines show that changing clinical practice is not an easy task [25, 26]. The publication and dissemination of guidelines alone is usually not enough to change the behaviour of health care providers [27]. The development of effective implementation strategies in this area remains a challenge.

Future developments in research and guideline development

The present study was primary aimed at presenting an update of the current clinical guidelines for the management of low back pain in primary care. Clinical guidelines focused at secondary care settings, occupational care settings, or specific subgroups of patients with lumbosacral radicular syndrome were not considered. Separate studies need to be undertaken to present an overview for these settings.

We assessed various aspects of the guideline development in Table 3. A formal assessment of the quality, e.g. with the AGREE instrument was not included. This was the topic of a separate paper which concluded that the quality of the guidelines indeed has improved over time [7].

The development of future guidelines in this field may benefit from previous experiences, evidence-based reviews, and various (inter) national guidelines as presented in this overview. The previous review of clinical guidelines listed 
the following recommendations (slightly modified) for the development of future guidelines in this field. Similar to a recent review on the quality of guidelines [7], this review shows that the quality of guidelines has improved over time and some of the recommendations have been followed. This includes recommendations 1, 3, and 4 (see below). For others, there still is room for improvement Recommendation 2 is not consistently applied. Recommendations 5 and 6 have improved over time, but not all recommendations in the guidelines are directly linked to the underlying evidence, and the process of the consensus methods used is not well described. Finally, the implementation strategies and the time frame of future updates are not well presented.

Recommendations for the development of future guidelines in the field of low back pain

1. Make use of available evidence-based reviews and previous clinical guidelines.

2. Include relevant non-English publications (if available).

3. Determine in advance the intended target groups (health care professions, patient population, and policy makers).

4. Be aware that the makeup of the guideline committee may have a direct impact on the content of the recommendations.

5. Specify exactly which recommendations are evidence-based and supply the correct references to each of these recommendations.

6. Specify exactly which recommendations are consensus-based and explain the process.

7. Determine in advance the implementation strategy, and set a time frame for future updates of the guideline.

Open Access This article is distributed under the terms of the Creative Commons Attribution Noncommercial License which permits any noncommercial use, distribution, and reproduction in any medium, provided the original author(s) and source are credited.

\section{References}

1. Koes BW, van Tulder MW, Thomas S (2006) Diagnosis and treatment of low back pain. BMJ 332(7555):1430-1434

2. Pengel L, Herbert R, Maher CG, Refshauge K (2003) Acute low back pain: systematic review of its prognosis. BMJ 327:323-327

3. Henschke N, Maher CG, Refshauge KM, Herbert RD, Cumming RG, Bleasel J, York J, Das A, McAuley JH (2008) Prognosis in patients with recent onset low back pain in Australian primary care: inception cohort study. BMJ 337:171. doi:10.1136/bmj. a171

4. Australian Institute of Health and Welfare (2004) Australia's Health 2004. AIHW, Canberra

5. Spitzer W (1987) Scientific approach to the assessment and management of activity-related spinal disorders. Spine 12:1-58

6. Koes BW, Van Tulder MW, Ostelo R et al (2001) Clinical guidelines for the management of low back pain in primary care: an international comparison. Spine 26:2504-2513

7. Bouwmeester W, van Enst A, van Tulder MW (2009) Quality of low back pain guidelines improved. Spine 34:2562-2567
8. Australian Acute Musculoskeletal Pain Guidelines Group (2003) Evidence-based management of acute musculoskeletal pain. Australian Academic Press, Bowen Hills

9. Friedrich M, Likar R (2007) Evidenz- und konsensusbasierte österreichische Leitlinien für das Management akuter und chronischer unspezifischer Kreuzschmerzen. Wien Klin Wochenschr 119(5-6):189-197

10. Rossignol M, Arsenault B, Dionne C et al (2007) Clinic on lowback pain in interdisciplinary practice (clip) guidelines. http://www.santpub-mtl.qc.ca/clip

11. Van Tulder MW, Becker A, Bekkering T et al (2006) European guidelines for the management of acute low back pain in primary care. Eur Spine J 15(Suppl 2):S169-S191

12. Airaksinen O, Brox JI, Cedraschi C et al (2006) European guidelines for the management of chronic non-specific low back pain. Eur Spine J 15(2):S192-S300

13. Malmivaara A, Erkintalo M, Jousimaa J, Kumpulainen T, Kuukkanen T, Pohjolainen T, Seitsalo S, Österman H (2008) Aikuisten alaselkäsairaudet. (Low back pain among adults. An update within the Finnish Current Care guidelines). Working group by the Finnish Medical Society Duodecim and the Societas Medicinae Physicalis et Rehabilitationis, Fenniae. Duodecim 124:2237-2239

14. Agence Nationale d'Accreditation et d'Evaluation en Sante (2000) Guidelines department, diagnosis and management of acute low back pain ( $<3$ months) with or without sciatica \& diagnosis, management and follow-up of patients with chronic low back pain, Paris. www.anaes.fr or www.sante.fr

15. Drug Committee of the German Medical Society (2007) Recommendations for treatment of low back pain [in German]. Köln, Germany

16. Negrini S, Giovannoni S, Minozzi S et al (2006) Diagnostic therapeutic flow-charts for low back pain patients: the Italian clinical guidelines. Euro Medicophys 42(2):151-170

17. National Health Committee (2004) National Advisory Committee on Health and Disability, Accident Rehabilitation and Compensation Insurance Corporation. New Zealand Acute Low back pain Guide. Wellington, New Zealand

18. Laerum E, Storheim K, Brox JI (2007) New clinical guidelines for low back pain. Tidsskr Nor Laegeforen 127(20):2706

19. Spain, the Spanish Back Pain Research Network (2005) Guia de practica clinica. Lumbalgia Inespecifica. Version espnola de la Guia de Practica Clinica del Programa Europeo COST B13

20. The Dutch Institute for Healthcare Improvement (CBO) (2003) Clinical guideline for non-specific low back pain [in Dutch]

21. Back pain (low) and sciatica. www.cks.library.nhs.uk. Accessed Sept 2008

22. Chou R, Qaseem A, Snow V et al (2007) Clinical Efficacy Assessment Subcommittee of the American College of Physicians American College of Physicians American Pain Society Low back pain Guidelines Panel Diagnosis and treatment of low back pain: a joint clinical practice guideline from the American College of Physicians and the American Pain Society. Ann Intern Med 147(7):478-491

23. Van der Roer N, Goossens ME, Evers SM, van Tulder MW (2005) What is the most cost-effective treatment for patients with low back pain? A systematic review. Best Pract Res Clin Rheumatol 19(4):671-684

24. Jellema $P$, van der Windt DA, van der Horst HE, Blankenstein $\mathrm{AH}$, Bouter LM, Stalman WA (2005) Why is a treatment aimed at psychosocial factors not effective in patients with (sub)acute low back pain? Pain 118(3):350-359

25. Bekkering GE, van Tulder MW, Hendriks EJM, Koopmanschap MA, Knol DL, Bouter LM, Oostendorp RAB (2005) Implementation of clinical guidelines on physical therapy for patients with low back pain: randomized trial comparing patient outcomes after 
a standard and active implementation strategy. Phys Ther 85(6):544-555

26. Engers AJ, Wensing M, van Tulder MW, Timmermans A, Oostendorp RA, Koes BW, Grol R (2005) Implementation of the Dutch low back pain guideline for general practitioners: a cluster randomized controlled trial. Spine 30(6):595-600
27. Becker A, Leonhardt C, Kochen MM, Keller S, Wegscheider K, Baum E, Donner-Banzhoff N, Pfingsten M, Hildebrandt J, Basler HD, Chenot JF (2008) Effects of two guideline implementation strategies on patient outcomes in primary care: a cluster randomized controlled trial. Spine 33(5):473-480 